\title{
Septal Structure and Mating Behaviour of Common $A$ Diploid Strains of Coprinus lagopus
}

\author{
By LORNA A. CASSELTON \\ Department of Plant Biology and Microbiology, Queen Mary College, \\ Mile End Road, London E. I \\ AND D. LEWIS AND R. MARCHANT* \\ Department of Botany and Microbiology, University College London, \\ Gower Street, London W.C. I \\ (Accepted for publication 27 March 197I)
}

\begin{abstract}
S UMMAR Y
Conversion of dolipore septa to simple septa in monokaryotic mycelia of Coprinus lagopus facilitates nuclear migration and is controlled by the $B$ incompatibility gene. In a common $A$ heterokaryon, which has two kinds of haploid nuclei with different alleles of the $B$ gene, both dolipore septa and simple septa were observed. A common $A$ diploid mycelium, derived from this heterokaryon and therefore of identical genotype, had no simple septa. This difference between the heterokaryon and the diploid is attributed to a different distribution of the two $B$ alleles in the cells of the mycelia. When all the cells contain two different $B$ alleles, as occurs in the diploid, the dolipore septa are not broken down. Moreover, in matings with other haploid and diploid strains, nuclei cannot migrate through the mycelium of the diploid. It is suggested that the septa in the diploid are no longer susceptible to enzymic degradation.
\end{abstract}

\section{INTRODUCTION}

The incompatibility system of the tetrapolar basidiomycetes Coprinus lagopus and Schizophyllum commune has received considerable attention because it represents a relatively simple example of morphogenesis, the control of which can be studied both genetically and biochemically. Matings between monokaryons with different alleles at both the $A$ and $B$ incompatibility loci give rise to the characteristic dikaryotic mycelium with binucleate cells and clamp connexions at all cross-walls. If mated monokaryons have a common allele at either the $A$ or $B$ locus, a heterokaryon is established which exhibits only part of the morphogenetic sequence leading to dikaryon formation. Thus it has been shown that the $A$ gene controls conjugate nuclear division and clamp cell formation. The $B$ gene controls nuclear migration prior to establishment of the dikaryon and clamp cell fusion (Swiezynski \& Day, I960; Raper, 1966).

The control by the $B$ gene of widespread nuclear migration through an established mycelium has been of special interest in view of the complex septal pore apparatus (the dolipore) found in basidiomycete mycelia. Conversion of dolipore septa to simple septa has been observed in compatible matings and in common $A$ heterokaryons of both Coprinus lagopus and Schizophyllum commune (Giesy \& Day, I965; Jersild, Mishkin \& Niederpruem, 1967)

\footnotetext{
* Present address: School of Biological and Environmental Studies, New University of Ulster, Coleraine, County Londonderry, Northern Ireland.
} 
and must facilitate nuclear migration. In heterokaryons with common $B$ alleles, nuclear migration does not occur and simple septa are not found.

Mutant and diploid strains provide additional material for studying incompatibility control. Primary mutations of the $B$ gene in Schizophyllum commune, first described by Parag (1962), result in complete breakdown of $B$ incompatibility control. Mutant $B$ strains with different $A$ alleles are fully compatible and form normal dikaryons. The mutant $B$ monokaryons, moreover, resemble common $A$ heterokaryons in general morphology and in irregular nuclear distribution resulting from active nuclear migration (Raper \& Raper, 1966). Koltin \& Flexer (1969) have shown that soon after spore germination the dolipore septa in the mycelia of these mutants become disrupted. Thus $B$ functions are fully expressed as a result of mutation in the $B$ gene.

In contrast, common $A$ diploid strains of Coprinus lagopus, heteroallelic for the $B$ gene, are self-incompatible (Casselton \& Lewis, 1966). In the present study further evidence for complete maintenance of incompatibility control in heteroallelic diploids has been obtained by examination of the septa. However, such diploids are also shown to exhibit a unilateral mating behaviour which suggests that septal disruption is no longer possible.

\section{METHODS}

Culture. Media and general culture techniques were those used by Lewis (I96I). All cultures were incubated at $37^{\circ}$.

Synthesis of diploid strains. Common $A$ and common $A B$ diploid strains were synthesized from appropriate common $A$ and common $A B$ heterokaryons respectively by the method of Casselton (1965).

Matings. Two methods were used to determine the ability of diploid strains to accept and donate nuclei in matings. (a) Inocula of the two strains to be tested were placed $\mathrm{I} \mathrm{cm}$. apart on complete medium and allowed to grow together. (b) One strain was allowed to form a small colony on complete medium and the second strain was then inoculated near to it. When possible, the second strain acted as a nuclear donor. This method was modified in some haploid-diploid matings by growing the diploid strain on minimal medium in an attempt to force it to accept nuclei from an auxotrophic haploid strain inoculated subsequently. The appearance of dikaryotic hyphae was easily detectable by the acute angle of the branching and the regular clamp connexions.

Electron microscopy. The material for electron microscopy was obtained by growing the organism on Visking dialysis tubing laid over the nutrient agar surface. Samples were taken by removing the dialysis tubing and cutting it into small pieces for fixation. Samples were fixed in $3 \%(\mathrm{v} / \mathrm{v})$ acrolein buffered at $\mathrm{pH} 7.2$ with sodium cacodylate for $\mathrm{I} h$. at $25^{\circ}$, followed by postfixation for $2 \mathrm{~h}$. at $\mathrm{o}^{\circ}$ in $\mathrm{I} \%(\mathrm{w} / \mathrm{v})$ osmic acid buffered at $\mathrm{pH} 7 \cdot 2$ with sodium cacodylate. Further treatment involved staining in uranyl acetate, dehydration in tertiary butanol mixtures and embedding in araldite (Marchant, 1969). Sections were cut with a diamond knife on an LKB Ultratome, stained with lead citrate (Reynolds, 1963) and examined in a Siemens Elmiskop I.

\section{RESULTS}

\section{Septa}

The septa in a common $A$ heterokaryon and a common $A$ diploid monokaryon derived from this heterokaryon were examined. As expected from the work of Giesy \& Day (1965), both complex and simple septa were observed in the heterokaryotic mycelium (Fig. I, 2). 

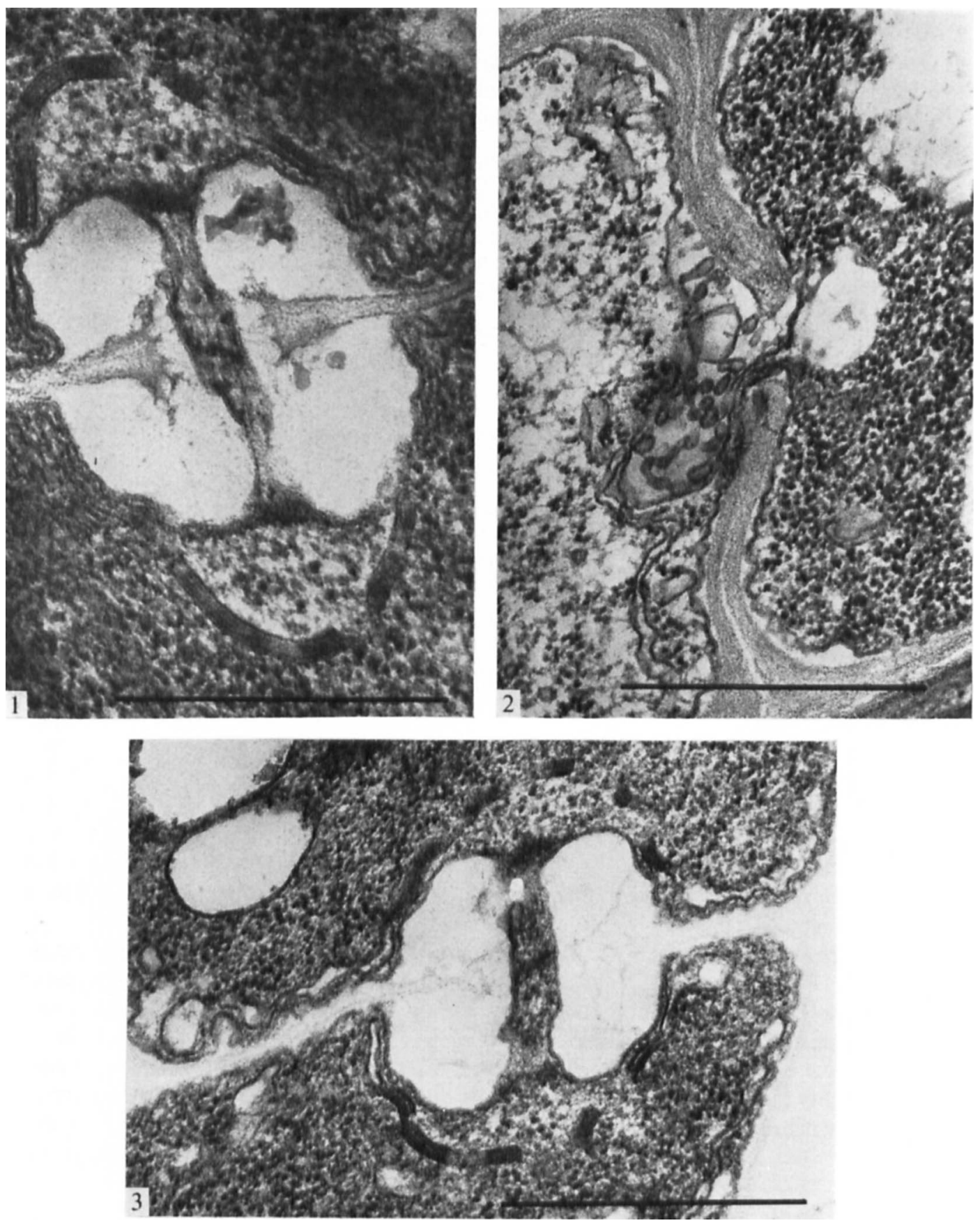

All scale markers represent $0.5 \mu \mathrm{m}$.

Fig. I. Section through a hypha of a common $A$ heterokaryon of Coprinus lagopus, showing an intact dolipore septum.

Fig. 2. Section through a hypha of a common $A$ heterokaryon of Coprinus lagopus, showing breakdown of a dolipore septum to yield a simple septum.

Fig. 3. Section through a hypha of a common $A$ diploid of Coprinus lagopus, showing an intact dolipore septum. 
However, only complex dolipore septa were found in the mycelium of the diploid (Fig. 3). No evidence was found to suggest conversion of any of these dolipore septa to simple septa.

The heterokaryon and the diploid are of identical genotype so the only difference in these mycelia is the distribution of $B$ alleles in the individual cells. In the heterokaryon the nuclei and thus the two $B$ alleles are distributed irregularly, whereas in the diploid all cells have both $B$ alleles.

\section{Mating behaviour}

A characteristic feature of primary mutant $B$ strains of Schizophyllum commune is their unilateral mating behaviour (Parag, 1962). Mutants always act as donors of nuclei in dikaryotization and do not accept nuclei. This is, perhaps, surprising in view of the presence of simple septa in the hyphae. In view of the different septal organization in mutants and heteroallelic $B$ diploids, it was thought worth re-investigating the mating behaviour of diploid strains of Coprinus lagopus.

Table I. Behaviour of diploid strains in haploid-diploid matings

$$
\text { Mating }
$$

$\begin{aligned} \text { Common } A \text { diploid } A_{6} A_{6} B_{3} B_{8} & \times A_{2} B_{3} \\ & \times \\ & \times A_{2} B_{6} \\ & \times A_{5} B_{5} \\ \text { Common } A B \text { diploid } A_{6} A_{6} B_{3} B_{3} & \times A_{5} B_{5}\end{aligned}$

\section{Reaction}

Semi-common $B$ $\left.\begin{array}{l}\text { Semi-common } B \\ \text { Compatible }\end{array}\right\}$

Compatible
Unilateral; diploid donor

Bilateral

Table 2. Behaviour of diploid strains in diploid-diploid matings

\begin{tabular}{lllll} 
& Mating & & & \multicolumn{1}{c}{ Reaction } \\
Common $A A_{6} A_{6} B_{6} B_{3}$ & $\times$ & common $A A_{5} A_{5} B_{5} B_{2}$ & Compatible & Junction \\
Common $A B A_{6} A_{6} B_{3} B_{3}$ & $\times$ & common $A B A_{5} A_{5} B_{5} B_{5}$ & Compatible & Bilateral \\
Common $A A_{2} A_{2} B_{6} B_{3}$ & $\times$ & common $A B A_{5} A_{5} B_{5} B_{5}$ & Compatible & Unilateral; \\
& $\times$ & & & common $A$ donor \\
Common $A A_{2} A_{2} B_{6} B_{5}$ & $\times B A_{5} A_{5} B_{5} B_{5}$ & Semi-common $B$ & $\begin{array}{c}\text { Unilateral; } \\
\text { common } A \text { donor }\end{array}$
\end{tabular}

Contrary to a previous report (Casselton, 1965), common $A$ diploids behave like mutant $B$ strains of Schizophyllum commune and act solely as donors of nuclei in both semi-compatible and fully compatible matings (Table I). In matings between different common $A$ diploids, dikaryotic growth appeared only at the junction of the two mated mycelia. That inability to accept nuclei is not due to diploidy as such was shown by testing the mating behaviour of common $A B$ diploids. Common $A B$ diploids both accepted and donated nuclei in all matings except those involving common $A$ diploids (Table 2). Unilateral mating behaviour of common $A$ diploids is, therefore, correlated with heteroallelism of the $B$ gene. Since incompatibility control in these diploids is clearly different from that in mutant $B$ strains, the similarity in mating behaviour may be only fortuitous.

\section{DISCUSSION}

The two morphogenetic events associated with $B$ gene expression are disruption of the dolipore septum and clamp cell fusion. Attention has already been drawn to the fact that these both involve localized breakdown of cell membranes and wall material (Casselton \& Lewis, 1966).

A further similarity is found when the distribution of $B$ alleles at the time of clamp fusion or septal disruption is considered. In the dikaryon, prior to clamp fusion, a unique situation 
has been created by separation of the two nuclear types into different cells. One nucleus is cut off in the clamp cell and the other in the penultimate hyphal cell. Fusion of the clamp cell with the penultimate cell occurs only if both these cells have at least one different $B$ allele. Thus in $B_{1} \times B_{1}$ and $B_{1} / B_{2} \times B_{1} / B_{2}$ matings both cells have common $B$ alleles and clamp fusion fails. On the other hand, in $B_{1} \times B_{2}, B_{1} \times B_{1} / B_{2}$ and $B_{1} / B_{2} \times B_{1} / B_{3}$ matings both cells have at least one different $B$ allele and clamp fusion occurs (Casselton \& Lewis, 1966). An analogous situation obtains with respect to septal disruption in monokaryons. In compatible matings and common $A$ heterokaryons, where a $B_{2}$ nucleus is migrating through a $B_{1}$ mycelium, a cell containing the migrating nucleus will have $B_{1}+B_{2}$ but be adjacent to a cell having only $B_{1}$. This is exactly similar to the $B_{1} / B_{2} \times B_{1}$ clamp situation and septal disruption occurs. However, all cells of a common $A$ diploid monokaryon will contain the same two $B$ alleles and, as the present work shows, $B$ function is not expressed.

Despite the similarities, there is both genetical and biochemical evidence which suggests that different regulation of the $B$ functions occurs in the monokaryon and the dikaryon. Mutant $B$ strains of Schizophyllum commune form stable dikaryons with normal clamp connexions and binucleate cells (Parag, 1962). This would be unlikely if the dolipore septa were converted to simple septa in the dikaryon, as they have been shown to be in the monokaryon (Koltin \& Flexer, 1969). Particularly interesting are the biochemical studies of $S$. commune (Wessels \& Niederpruem, 1967; Wessels, 1969; Niederpruem \& Wessels, 1969). Mycelia in which septal disruption is known to be occurring, namely common $A$ heterokaryons, primary mutant $B$ monokaryons and compatible matings, have greatly increased intracellular levels of the cell wall degrading enzyme called R-glucanase. This enzyme has now been directly implicated in septal dissolution by Janszen \& Wessels (1970) using hyphal wall preparations of a monokaryon. Increased levels of R-glucanase in dikaryons occur after exhaustion of the carbon supply in the growth medium, being associated with fruit-body development. In contrast, exhaustion of the carbon source does not influence the level of the enzyme in monokaryons. This was interpreted to mean that there is a change in the mode of regulation of enzyme activity in the dikaryon (Niederpruem \& Wessels, I969). It is not known whether R-glucanase activity is also involved in clamp cell fusion, but the fact that common $A$ heterokaryons have an increased incidence of hyphal fusions (Raper \& Raper, I966) and also have high levels of this enzyme would suggest that it is.

Inability of common $A$ diploids to accept nuclei is associated with heteroallelism of the $B$ gene. This could mean that the septal disruption, necessary for nuclei to migrate through an established mycelium, cannot occur when all the cells have two different $B$ alleles. This is the $B$ situation normally found in the dikaryon which also cannot accept additional nuclei. Further, Moore (1965) has suggested that the dolipore septa may be structurally different in monokaryons and dikaryons. A change in the chemical composition of the septa, when the $B$ gene is heteroallelic, could protect the septa from enzymic degradation. This would preserve the important binucleate condition of the cells of the dikaryon under all conditions and provide a simple explanation for the unilateral mating behaviour of common $A$ diploids. This possibility could be tested in Schizophyllum commune by analogous experiments to those already reported by Janszen \& Wessels (1970).

\section{REFERENCES}

Casselton, L. A. (1965). The production and behaviour of diploids of Coprinus lagopus. Genetical Research 6, 190-208.

Casselton, L. A. \& Lewis, D. (1966). Compatibility and stability of diploids in Coprinus lagopus. Genetical Research 8, 6i-72. 
GIESY, R. M. \& DAY, P. R. (1965). The septal pores of Coprinus lagopus (Fr.) sensu Buller in relation to nuclear migration. American Journal of Botany 52, 287-293.

JANSzen, F. H. A. \& Wessels, J. G. H. (1970). Enzymic dissolution of hyphal septa in a basidiomycete. Antonie van Leeuwenhoek 36, 255-257.

Jersild, R., Mishkin, S. \& Niederpruem, D. J. (1967). Origin and ultrastructure of complex septa in Schizophyllum commune development. Archiv für Mikrobiologie 57, 20-32.

Koltin, Y. \& FleXer, A. S. (1969). Alteration of nuclear distribution in B-mutant strains of Schizophyllum commune. Journal of Cell Science 4, 739-749.

LEWIS, D. (1961). Genetic analysis of methionine suppressors in Coprinus. Genetical Research 2, I4I-155.

MARChaNT, R. (1969). The fine structure and development of the fructification of Lycoperdon perlatum. Transactions of the British Mycological Society 53, 63-68.

Moore, R. T. (1965). The ultrastructure of fungal cells. In The Fungi, vol. I, p. 95. Edited by G. C. Ainsworth \& A. S. Sussman. New York: Academic Press.

Niederpruem, D. J. \& Wessels, J. G. H. (1969). Cytodifferentiation and morphogenesis in Schizophyllum commune. Bacteriological Reviews 33, 505-535.

PARAG, Y. (1962). Mutations in the B incompatibility factor of Schizophyllum commune. Proceedings of the National Academy of Sciences of the United States of America 48, 743-750.

RAPER, J. R. (1966). Genetics of Sexuality in Higher Fungi. New York: Ronald Press Company.

RAPER, C. A. \& RAPER, J. R. (I966). Mutations modifying sexual morphogenesis in Schizophyllum. Genetics, Princeton 54, II5I-I 68.

REYNOLDS, E. S. (1963). The use of lead citrate at high $\mathrm{pH}$ as an electron-opaque stain in electron microscopy. Journal of Cell Biology 17, 208-2 I 2.

SwiEzynsky, K. M. \& DAY, P. R. (I960). Heterokaryon formation in Coprinus lagopus. Genetical Research I, 1 14-I 28.

Wessers, J. G. H. (1969). Biochemistry of sexual morphogenesis in Schizophyllum commune: Effect of mutations affecting the incompatibility system on cell-wall metabolism. Journal of Bacteriology 98, 697-704.

Wessels, J. G. H. \& NiederPRUEM, D. J. (I967). Role of a cell-wall glucan-degrading enzyme in mating of Schizophyllum commune. Journal of Bacteriology 94, I 594-1602. 